\title{
Mechanical Thrombectomy of Distal Occlusions in the Anterior Cerebral Artery: Recanalization Rates, Periprocedural Complications, and Clinical Outcome
}

\author{
(D). Pfaff, (D) C. Herweh, (DM. Pham, (D) S. Schieber, DP.A. Ringleb, (DM. Bendszus, and (D). Möhlenbruch
}

\begin{abstract}
BACKGROUND AND PURPOSE: Patients with acute ischemic stroke in the anterior circulation are at risk for either primary or, following mechanical thrombectomy, secondary occlusion of the anterior cerebral artery. Because previous studies had only a limited informative value, we report our data concerning the frequency and location of distal anterior cerebral artery occlusions, recanalization rates, periprocedural complications, and clinical outcome.
\end{abstract}

MATERIALS AND METHODS: We performed a retrospective analysis of prospectively collected data of patients with acute ischemic stroke undergoing mechanical thrombectomy in the anterior circulation between June 2010 and April 2015.

RESULTS: Of 368 patients included in this analysis, we identified 30 (8.1\%) with either primary $(n=17,4.6 \%)$ or secondary $(n=13,3.5 \%)$ embolic occlusion of the distal anterior cerebral artery. The recanalization rate after placement of a stent retriever was $88 \%$. Periprocedural complications were rare and included vasospasms $(n=3,10 \%)$ and dissection $(n=1,3.3 \%)$. However, 16 (53.5\%) patients sustained an (at least partial) infarction of the anterior cerebral artery territory. Ninety days after the ictus, clinical outcome according to the modified Rankin Scale score was the following: 0-2, $n=11$ (36.6\%); 3-4, $n=9$ (30\%); 5-6, $n=10$ (33.3\%).

CONCLUSIONS: Occlusions of the distal anterior cerebral artery affect approximately $8 \%$ of patients with acute ischemic stroke in the anterior circulation receiving mechanical thrombectomy. Despite a high recanalization rate and a low complication rate, subsequent (partial) infarction in the anterior cerebral artery territory occurs in approximately half of patients. Fortunately, clinical outcome appears not to be predominately unfavorable.

ABBREVIATIONS: $\mathrm{ACA}=$ anterior cerebral artery; $\mathrm{MT}=$ mechanical thrombectomy

M echanical thrombectomy (MT) is an effective treatment in acute ischemic stroke secondary to a large-vessel occlusion. ${ }^{1-4}$ Patients with acute ischemic stroke secondary to an occlusion of the internal carotid artery-T, middle cerebral artery trunk (M1), or MCA secondary division (M2) have relatively high rates of revascularization and favorable clinical outcomes after MT. ${ }^{5,6} \mathrm{Un}$ fortunately, for patients with ICA-T occlusions and MCA occlusions, there is a risk of approximately $8.6 \%-11.4 \%$ for secondary emboli

Received July 27, 2015; accepted after revision August 29.

From the Departments of Neuroradiology (J.P., C.H., M.P., M.B., M.M.) and Neurology (S.S., P.A.R.), University of Heidelberg, Heidelberg, Germany.

Mirko Pham, Christian Herweh, Simon Schieber, and Peter Arthur Ringleb contributed in data collection and reporting of this study. Johannes Pfaff, Martin Bendszus, and Markus Möhlenbruch had access to all data and supervised data collection and analysis, writing, and editing of article.

This work received no specific grant from any funding agency in the public, commercial, or not-for-profit sectors.

Please address correspondence to Johannes Pfaff, MD, University of Heidelberg, Department of Neuroradiology, Im Neuenheimer Feld 400, 69120 Heidelberg, Germany; e-mail: johannes.pfaff@med.uni-heidelberg.de

http://dx.doi.org/10.3174/ajnr.A4594 into the anterior cerebral artery (ACA), especially the distal branches such as the pericallosal artery, during MT. ${ }^{2,7,8}$ Although various technical possibilities, such as proximal flow control or combined aspiration, have been recommended to reduce the risk of secondary emboli ${ }^{9-13}$, occlusions of the distal ACA occur.

Regardless of the cause of the occlusion (primary occlusion or secondary emboli during MT), cerebral infarctions in the ACA territory may cause relevant clinical deficits by affecting the primary or supplementary motor areas. ${ }^{14}$ In a previous, relatively small patient cohort $(n=6)$, treatment of secondary ACA occlusions was technically successful in $80 \%$ of the cases and uneventful in all instances. ${ }^{7}$

We present data on the frequency and location of distal ACA occlusions, recanalization rates, periprocedural complications, and clinical outcome.

\section{MATERIALS AND METHODS Patient Selection}

On the basis of a prospectively collected patient cohort with acute ischemic stroke undergoing MT in the anterior circulation at our institution between June 2010 and April 2015, we 
selected patients with a primary or secondary embolic occlusion of the distal ACA for this retrospective analysis. We excluded patients with an absent or severely hypoplastic ipsilateral A1 segment and those with proximal occlusions of the A1 segment from this analysis.

\section{Stroke Therapy}

Our institution provides neurologic, neuroradiologic, and neurointerventional services within a maximum-care university hospital center serving more than 500,000 individuals within its county limits and nearly 2.3 million within a greater metropolitan area. For each patient, a stroke neurologist performed physical neurologic examinations and detailed assessment of the NIHSS score in the emergency department on admission. Patients with suspected acute ischemic stroke received a standardized stroke imaging protocol: either MR imaging (including axial DWI, axial FLAIR, axial SWI, TOF-MRA, contrast-enhanced MRA of the aortic arch and cervical arteries, and axial PWI) or CT (including a non-contrastenhanced CT, CT angiography, and perfusion CT) for assessment of their eligibility for intravenous rPA and MT. The decision between MR imaging and CT was made individually on the basis of the patient's condition, known or unknown time of symptom onset, MR imaging eligibility, and immediate availability of the MR imaging and CT scanners.

Administration and dosing of intravenous rtPA followed national and international guidelines and an institutional standard operating procedure. Patients were considered eligible for MT by the treating neurointerventionalist if an occlusion of a major intracranial artery was detected by CTA or MRA, therapy could be accomplished within 8 hours of onset, the NIHSS score was $\geq 8$ on evaluation, and the initial imaging excluded hemorrhage or a large infarct core of more than one-third of the middle cerebral artery territory or an ASPECTS of $<6$. In case of unknown onset of symptoms, patients were considered eligible for MT if stroke imaging ruled out a large infarct core and revealed a relevant, salvageable penumbra. No age limit was used as an inclusion or exclusion criterion for eligibility for MT, and the decision to perform MT was made individually on the basis of the patient's comorbidities, prestroke mRS, and the assumed choice of the patient. In case of fluctuating or progressive neurologic deficits, patients with minor symptoms (NIHSS score of $<8$ ) were treated as well.

Intraprocedural use of mechanical and/or pharmacologic treatments remained at the discretion of the treating neurointerventionalist. Microcatheters and stent retrievers used for MT in this patient cohort were subject to change due to technical development during the observation period. Between June 2010 and July 2013, general anesthesia, performed by experienced neurointensivists, was routinely administered during MT. Starting in August 2013, procedures were performed with the patient under conscious sedation as well. Independent of the performed management of sedation, patients received standardized peri-interventional management and monitoring of physiologic target values according to our in-house standard operating procedure at the discretion of the neurointensivist adapted to the patient and situation.

\section{Postinterventional Management}

All patients were observed in a neurologic intensive care unit after MT. The aim was transfer to the stroke unit as soon as possible, depending on the condition of the patient. Follow-up imaging (either CT or MR imaging) was routinely performed at 20-36 hours after treatment, or earlier if neurologic deterioration occurred. Postinterventional NIHSS and mRS were assessed by detailed physical examinations performed by an independent stroke neurologist at discharge. Follow-up data after 3 months were obtained by an in-patient visit or a telephone call by a neurologist not blinded to the type of treatment. The modified Rankin Scale was used to measure the severity of the disability.

\section{Data Collection}

Data collection included baseline demographics (age and sex) and medical history (eg, hypertension, coronary artery disease, congestive heart failure, atrial fibrillation, diabetes mellitus, hypercholesterolemia, history of smoking, and previous stroke) and symptom onset time and stroke severity as measured by the NIHSS. The time of initiation of stroke imaging and the time of start of angiography were captured automatically by the CT scanner and angiography system. The onset and duration of occlusion (secondary emboli) and time of recanalization were evaluated according to the timestamp of the referring angiographic image. Vessel diameter and location of the occlusion were assessed on angiographic images as well. The location of the occlusion was categorized following the segmentation of the ACA with regard to its anatomic position relative to the corpus callosum and the origin of the frontopolar artery, orbitofrontal artery, callosomarginal artery, and distal branches as characterized by Lehecka et al. ${ }^{15}$ Devices and medication used during the interventional procedures, number of thrombectomy maneuvers, and intraprocedural complications were evaluated according to the treatment protocols. Angiographic outcome by TICI and complications (eg, vessel perforation, dissection of the anterior cerebral artery) were assessed by a senior neurointerventionalist. The incidences of cerebral infarction, parenchymal hemorrhage (by criteria of the second European-Australasian Acute Stroke Study [ECASS II] $)^{16}$ ), or subarachnoid hemorrhage were assessed by using routinely performed follow-up imaging. Clinical outcome was evaluated according to the modified Rankin Scale.

\section{Statistical Analysis}

We compared data by using the $\chi^{2}$ test for categoric variables. $P<$ .05 was considered significant in the final model. All statistical analyses were performed by using SPSS 21.0.0.0 (IBM, Armonk, New York).

\section{Ethics Approval}

The study was approved by our local ethics committee.

\section{RESULTS}

Between June 2010 and April 2015, 388 patients underwent MT due to an acute ischemic stroke in the anterior circulation at our institution. Twenty of 388 (5.2\%) patients were excluded because of an absent or severely hypoplastic ipsilateral A1 segment. Among the remaining 368 patients, we identified 30 (8.1\%) with 
a distal ACA occlusion (for patient baseline characteristics, see Table 1). The distal ACA occlusion was, according to initial angiographic imaging, preexisting in 17/368 (4.6\%) cases and occurred in $13 / 368(3.5 \%)$ patients secondary to a recanalization maneuver (for distal ACA occlusion sites, see Table 2).

Mechanical thrombectomy with a stent retriever was intended for all patients, but a stent retriever could not be deployed in $5 / 30(16.6 \%)$ because placement of a guidewire $(n=$ $1,3.3 \%$; occlusion in the middle pericallosal artery [superior

Table 1: Baseline characteristics of patients with a distal anterior cerebral artery occlusion

\begin{tabular}{|c|c|}
\hline Characteristics & Patients $(N=30)$ \\
\hline Age (yr), mean (SD) & $64(13)$ \\
\hline Male & $14(46.6 \%)$ \\
\hline Hypertension & $20(66.6 \%)$ \\
\hline Diabetes mellitus & $5(16.6 \%)$ \\
\hline Atrial fibrillation & $13(43.3 \%)$ \\
\hline Coronary artery disease & $3(10 \%)$ \\
\hline Congestive heart failure & $2(6.6 \%)$ \\
\hline Hypercholesterolemia & $8(26.6 \%)$ \\
\hline Previous stroke & $0(0 \%)$ \\
\hline History of smoking & $3(10 \%)$ \\
\hline \multicolumn{2}{|l|}{ Prestroke mRS } \\
\hline 0 & $22(73.3 \%)$ \\
\hline 1 & $5(16.6 \%)$ \\
\hline 2 & $3(10 \%)$ \\
\hline Initial NIHSS score, median (IQR) & $18(13-23)$ \\
\hline $\begin{array}{l}\text { Time from stroke onset to initial imaging } \\
\text { (min), median (IQR) }\end{array}$ & $90(61-155)$ \\
\hline $\mathrm{CT}$ & 16 \\
\hline MR & 14 \\
\hline \multicolumn{2}{|l|}{$\begin{array}{l}\text { Time from stroke onset to imaging } \\
\text { (min), median (IQR) }\end{array}$} \\
\hline $\mathrm{CT}$ & $76(55-150)$ \\
\hline MR & $154(87-230)$ \\
\hline \multicolumn{2}{|l|}{ ASPECTS ${ }^{\mathrm{a}}$, median (IQR) } \\
\hline CT & $9(9)$ \\
\hline MR & $7(7-9)^{b}$ \\
\hline \multicolumn{2}{|l|}{ Initial occlusion site } \\
\hline ICA (excluding Carotid-T) & $1(3.3 \%)$ \\
\hline Carotid-T & $18(60 \%)$ \\
\hline M1 & $9(30 \%)$ \\
\hline M2 & $2(6.6 \%)$ \\
\hline Intravenous tPA & $25(83.3 \%)$ \\
\hline $\begin{array}{l}\text { Time from stroke onset to groin puncture } \\
\text { (min), median (IQR) }\end{array}$ & 211 (139-289) \\
\hline
\end{tabular}

segment]), or placement of a microcatheter behind the thrombus was not possible $(n=4,13.3 \%$; occlusion in the middle pericallosal artery [inferior segment, $n=1$ ], distal pericallosal artery $[n=2]$, and callosomarginal artery $[n=1])$. In 2 of these cases $(6.6 \%)$, intra-arterial rtPA ( $5 \mathrm{mg}$ and $2 \mathrm{mg}$, respectively) was administered immediately at the occlusion via a microcatheter. In consideration of the time window and possible risks, there was no further treatment in the other $3(10 \%)$ cases. Deployment of a stent retriever was achieved and MT was performed in 25/30 (83.3\%) patients (for type and manufacturer of the devices used as well as the number of MT maneuvers performed, see Table 3 ).

\section{Angiographic Outcome}

Recanalization of the distal ACA occlusion (TICI 2b/3) was achieved in 22/30 (73.3\%) patients. However, in each of these 22 patients, at least 1 stent-retrieval maneuver was performed. With regard to all patients in whom placement of a stent retriever was possible $(n=25)$, the accumulated recanalization rate (TICI $2 \mathrm{~b} / 3$ ) was $88 \%$ (Fig 1). Recanalization after a single retrieval maneuver occurred in $17 / 30(56.6 \%)$ cases with a distal ACA occlusion, and in $68 \%(17 / 25)$ of all patients in whom placement of a stent retriever was possible. None of the patients in whom a stent retriever could not be properly placed achieved TICI $2 \mathrm{~b} / 3$ (5/30, $16.6 \%$ ). In 3 cases in which stent retrievers were used (Aperio; Acandis, Pforzheim, Germany; Revive; Codman Neurovascular, Raynham, Massachusetts; and Solitaire FR; Covidien, Irvine, California, respectively), recanalization could not be achieved. With

Table 3: List of types, manufacturers, and number of passes of devices used for mechanical thrombectomy

\begin{tabular}{|c|c|c|c|c|}
\hline Device & Manufacturer & $\begin{array}{c}\text { Size } \\
(\mathrm{mm})\end{array}$ & $\begin{array}{c}\text { No. of } \\
\text { Patients } \\
\text { Treated }\end{array}$ & $\begin{array}{l}\text { Total No. } \\
\text { of Passes }\end{array}$ \\
\hline Aperio $^{a}$ & Acandis & $4.5 \times 30$ & 1 & 3 \\
\hline Capture $^{a}$ & MindFrame ${ }^{b}$ & $4.0 \times 20$ & 1 & 2 \\
\hline Catch Mini ${ }^{\mathrm{a}}$ & Balt ${ }^{c}$ & $3 \times 15$ & 3 & 4 \\
\hline $\mathrm{ERIC}^{\mathrm{a}}$ & MicroVention & $4 \times 24$ & 1 & 1 \\
\hline Revive $^{d}$ & Codman & $4.5 \times 22$ & 6 & 9 \\
\hline Solitaire FR ${ }^{d}$ & Covidien & $4 \times 20$ & 12 & 17 \\
\hline Trevo ProVue ${ }^{d}$ & Stryker $^{\mathrm{e}}$ & $4 \times 20$ & 1 & 2 \\
\hline \multicolumn{5}{|c|}{$\begin{array}{l}\text { a Devices fitting through .017-inch microcatheters (eg, Headway 17; MicroVention). } \\
\text { b Irvine, California. } \\
\text { c Montmorency, France. } \\
{ }^{d} \text { Devices fitting through .021-inch microcatheters (eg, Rebar 18; Covidien), and .027- } \\
\text { inch microcatheters (Revive, Codman Neurovascular; Rebar 27, Covidien). } \\
\text { e Kalamazoo, Michigan. }\end{array}$} \\
\hline
\end{tabular}

Table 2: Occlusion site and vessel diameter of the anterior cerebral artery

\begin{tabular}{|c|c|c|c|}
\hline Occlusion Site & Total $(N=30)$ & $\begin{array}{c}\text { Vessel Diameter (mm), } \\
\text { mean (SD) }\end{array}$ & $\begin{array}{c}\text { No. of Device Passes }{ }^{a} \\
\text { mean (SD) }\end{array}$ \\
\hline $\begin{array}{l}\text { Proximal pericallosal artery }=\mathrm{A} 2 \text { segment (between AcomA and } \\
\text { genu of corpus callosum) } \\
\text { Middle pericallosal artery }=\mathrm{A} 3 \text { segment (curving around genu of } \\
\text { corpus callosum) }\end{array}$ & $7(23.3 \%)$ & $1.9(0.4)$ & $1.28(0.69)$ \\
\hline Inferior segment & $6(20 \%)$ & $1.8(0.2)$ & $2(1.26)$ \\
\hline Anterior segment & $2(6.6 \%)$ & $2.1(0.3)$ & $1.5(0.5)$ \\
\hline Superior segment & $8(26.6 \%)$ & $1.7(0.4)$ & $1.57(0.72)$ \\
\hline \multicolumn{4}{|l|}{ Distal pericallosal artery } \\
\hline A4 and A5 segments and distal branches other than CMA & $5(16.6 \%)$ & $1.7(0.4)$ & $1(0)$ \\
\hline CMA & $2(6.6 \%)$ & $1.5(0.1)$ & $1(0)$ \\
\hline
\end{tabular}

Note:-AcomA indicates anterior communicating artery; CMA, callosomarginal artery.

${ }^{a}$ In patients in whom placement of a stent retriever was possible. 


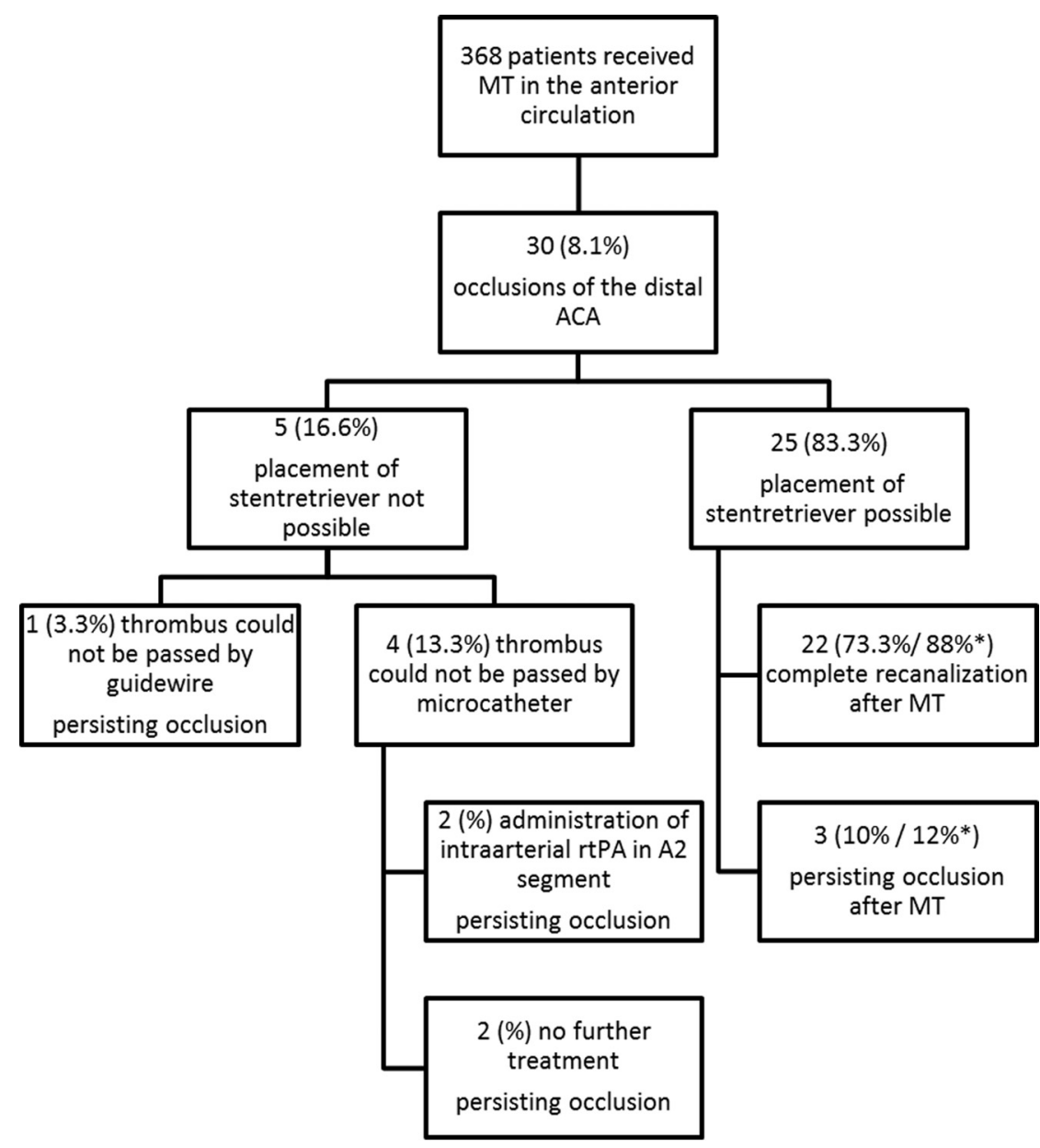

FIGURE Flowchart of treatments of distal ACA occlusions. The asterisk indicates the percentage of the overall successful stent-retriever placements.

regard to the possible risk of vessel injury and/or rupture, no other devices were used, and no further recanalization maneuvers were performed in these patients.

\section{Intraprocedural Complications and Frequency of Infarction and Hemorrhage in the ACA Territory}

There were 3 cases of vasospasms in the distal ACA following a retrieval maneuver in the superior A3 segment $(n=2)$ and the callosomarginal artery $(n=1)$. In 2 cases, the vasospasms resolved completely after intra-arterial administration of nimodipine into the affected segment via a microcatheter. The third case of vasospasm was self-limiting within 5 minutes without further treatment.

A dissection of the distal ACA (A4/A5 segment) with minimal distal flow impairment occurred in 1 patient after thrombectomy. Considering the risk of further manipulation and the location of the dissected vessel, no further treatment was considered. According to the imaging data and treatment protocols, there was no vessel perforation with secondary hemorrhage. We did not observe secondary emboli from the ACA into a new vascular territory. Furthermore, no air emboli or device detachment was observed.

Follow-up imaging revealed partial or complete ACA infarction in $16 / 30(53.3 \%)$ patients, 11 of whom had a primary and 5 of whom had a secondary occlusion. The frequency of infarction between both groups was, however, not significantly different in this small patient cohort $(P=.153)$. There was only 1 case $(3.3 \%)$ with hemorrhagic transformation in the ACA territory (superior frontal gyrus) with confluent petechiae within the infarcted area, but without space-occupying effect (HI2, according to ECASS II criteria). Four of 30 (13.3\%) patients exhibited angiographically occult, selflimiting, minimal SAH in the ipsilateral Sylvian fissure detected on follow-up CT imaging. SAHs were estimated to be caused by recanalization maneuvers in the distal MCA (M2 segment) in these patients. None of the patients experienced SAH in the anterior cerebral artery territory.

\section{Clinical Outcome}

Ninety days after the ictus, clinical outcome according to the modified Rankin Scale score was the following: $0-2, n=$ $11(36.6 \%) ; 3-4, n=9(30 \%) ; 5-6, n=$ $10(33.3 \%)$.

\section{DISCUSSION}

ACA emboli may occur before or during intra-arterial treatment of an ICA or MCA occlusion. The frequency of new emboli during IV, intra-arterial, or combined IV-intra-arterial treatment of a large-vessel occlusion in the anterior circulation has been reported to be between $1.7 \%$ and $15 \% .^{7,8,17}$ In our patient cohort, the rate of new distal ACA emboli secondary to a recanalization maneuver was lower (3.5\%). Similar to secondary emboli, a relatively low frequency of primary distal ACA occlusions $(4.6 \%)$ occurred. However, in combination, about $8 \%$ of all patients with a large-vessel occlusion of the anterior circulation receiving MT had a distal ACA occlusion, which is consistent with the results from the Multicenter Randomized Clinical Trial of Endovascular Treatment for Acute Ischemic Stroke in the Netherlands (MR CLEAN) trial. ${ }^{2}$ If one assumes that following the publication of recent study data on thrombectomy ${ }^{1-3,18}$ the frequency of patients receiving MT will increase, distal ACA occlusions and the corresponding prevention and treatment options will become an even more relevant topic than they are today.

Because recanalization is a predictor of good clinical outcome, ${ }^{19}$ high recanalization rates should be achieved. Considering the risk of an infarction and possible neurologic deficits following an ACA occlusion ${ }^{14}$ and against the background of positive experience in the treatment of distal M2 occlusions, ${ }^{20}$ interventional neuroradiologists are urged to consider treatment of distal ACA occlusions to achieve high recanalization rates. In 
our patient cohort, the recanalization rate was $73.3 \%$ of all distal ACA occlusions, respectively, $88 \%$ after successful placement of a stent retriever. This is comparable with recanalization rates of $\mathrm{M} 1$ or M2 occlusions after MT. ${ }^{20-22}$ In 4 (13.3\%) patients, placement of a microcatheter behind the thrombus was not possible. However, these cases were in 2010 and early 2012 when only "large" microcatheters (Rebar-18 and Rebar-27; Covidien) were available at our site. With the introduction of smaller microcatheters and stent retrievers, successful retrieval maneuvers in small and/or tortuous distal intracranial vessels will probably be easier. ${ }^{23}$ For example, the outside diameter of the device-delivering microcatheter could be reduced by $29 \%$ by using a Headway 17 microcatheter (1.7F; MicroVention, Tustin, California) instead of a Rebar-18 microcatheter $(2.4 \mathrm{~F})$. Thus, our department started using microcatheters with a 0.017 -inch inner diameter in selected cases in the second quarter of 2012, when placement of our standard microcatheter (0.021-inch inner diameter) was not possible. So far, virtually every distal occlusion could be reached successfully.

The risk of periprocedural complications with MT in distal ACA occlusions does not seem be higher than that in the MCA. We experienced 1 case of dissection (3.3\%) and 3 cases of vasospasm $(10 \%)$ but no case of symptomatic intracranial hemorrhage into the ACA territory. In comparison, the frequency of dissection $(1.8 \%-4.5 \%)$, vasospasm $(3 \%-22.5 \%$, including asymptomatic vasospasm), and symptomatic intracranial hemorrhage $(5 \%-10.9 \%)$ was reported within the same range or even higher during endovascular treatment of MCA occlusions. $^{21,24,25}$

Independent of the underlying cause of the occlusion, primary occlusion or thrombus fragmentation and secondary emboli as a by-product of recanalization maneuvers, occlusions of the ACA may cause infarction and significant neurologic deficits. ${ }^{14}$ Despite a high recanalization rate, ipsilateral infarction (at least partial) in the ACA territory occurred in $53.5 \%$ of our cases. This relatively high rate of ACA territory infarction might be secondary to insufficiency or absences of collaterals in the setting of concurrent or preceding ICA or MCA occlusion. ${ }^{26,27}$ With a frequency of $38.5 \%$ of ACA infarction in patients with secondary emboli, our data are comparable with those in previous studies, in which the frequency was reported to be $32 \%$ and $40 \%$, respectively. ${ }^{7,8}$ Because primary occlusions are present longer than secondary occlusions before recanalization, the frequency of ACA infarction in patients with primary occlusions was higher (64.7\%). However, our analysis did not reach statistical significance for this matter $(P=.153)$. This finding should be viewed cautiously. A larger patient population might demonstrate a significant difference and, following the law of stroke (time is brain ${ }^{28}$ ), probably with a disadvantage for primary occlusions.

Compared with outcomes in recent clinical trials, clinical outcomes after 90 days were not predominately ${ }^{1-3}$ unfavorable in this patient cohort. This outcome might be because of the following: a possible MCA and ACA territory infarction, due to a larger infarct volume and/or the involvement of the supplementary motor cortex. $^{14,29}$

\section{Limitations}

This analysis has several limitations. First, because this article focusses on occlusions of the distal ACA, the overall occurrence of occlusions of the ACA (including the Al segment) is likely to be higher. Under this premise, our data might underestimate the frequency of occlusions and infarctions in the ACA territory.

Second, allocation of clinical deficits to the ACA territory is, especially in patients with concurrent MCA infarction, not always possible. Therefore, comparison of clinical outcome of these patients with those of patients with isolated MCA territory infarction needs to be viewed cautiously.

Third, because occlusions were treated with different revascularization devices, a recommendation of a specific device for treatment of distal ACA occlusions is not possible and was not the aim of the study. In this patient cohort and in the large interventional stroke trials, the standard approach for treatment of an intracranial vessel occlusion was MT by using a stent retriever. However, MT in distal cerebrovascular occlusions appears to be feasible even with a direct-aspiration first-pass technique. ${ }^{30}$ The smaller diameter and pronounced kinking of a vessel should be taken into account when choosing catheters and devices to minimize alteration of the vessel wall.

\section{CONCLUSIONS}

Occlusions of the distal ACA affect approximately $8 \%$ of patients with acute ischemic stroke in the anterior circulation undergoing MT. Despite a high recanalization rate and a low complication rate, subsequent (partial) infarction in the ACA territory occurred in approximately half of patients. Fortunately, clinical outcome appears not to be predominately unfavorable.

Disclosures: Christian Herweh—UNRELATED: Travel/Accommodations/Meeting Expenses Unrelated to Activities Listed: Travel accommodations and registration for the Live Interventional Neuroradiology \& Neurosurgery Course, 2015, paid by Covidien. Mirko Pham-UNRELATED: Grants/Grants Pending: M.P. is supported by a Memorial Stipend from Else Kröner-Fresenius-Stiftung*; Payment for Lectures (including service on Speakers Bureaus): M.P. received speaker honorarium from Penumbra Europe GmbH; Travel/Accommodations/Meeting Expenses Unrelated to Activities Listed: Travel expenses from Covidien. Peter A. Ringleb-UNRELATED: Consultancy: Advisory Boards for Boehringer Ingelheim, Daiichi Sankyo, and Covidien; Payment for Lectures (including service on Speakers Bureaus): Bayer, Daiichi Sankyo, Boehringer Ingelheim, Comments: Lectures; Travel/Accommodations/ Meeting Expenses Unrelated to Activities Listed: Boehringer Ingelheim, Bayer, Comments: travel support. Martin Bendszus_UNRELATED: Board Membership: Data Safety Monitoring Board Vascular Dynamics; Consultancy: Roche, Guerbet; Grants/ Grants Pending: Deutsche Forschungsgemeinschaft, ${ }^{*}$ Hopp Foundation, ${ }^{*}$ Novartis, ${ }^{*}$ Codman, ${ }^{\star}$ Guerbet, ${ }^{*}$ Siemens ${ }^{*}$; Payment for Lectures (including service on Speakers Bureaus): Guerbet, Novartis, Codman, Roche. Markus Möhlenbruch—UNRELATED: Board Membership: Codman Neurovascular; Consultancy: Acandis, MicroVention; Payment for Lectures (including service on Speakers Bureaus): Codman Neurovascular. *Money paid to the institution.

\section{REFERENCES}

1. Campbell BC, Mitchell PJ, Kleinig TJ, et al; EXTEND-IA Investigators. Endovascular therapy for ischemic stroke with perfusion-imaging selection. $N$ Engl J Med 2015;372:1009-18 CrossRef Medline

2. Berkhemer OA, Fransen PS, Beumer D, et al; MR CLEAN Investigators. A randomized trial of intraarterial treatment for acute ischemic stroke. N Engl J Med 2015;372:11-20 CrossRef Medline

3. Goyal M, Demchuk AM, Menon BK, et al; ESCAPE Trial Investigators. Randomized assessment of rapid endovascular treatment of ischemic stroke. N Engl J Med 2015;372:1019-30 CrossRef Medline

4. Möhlenbruch M, Seifert M, Okulla T, et al. Mechanical thrombectomy compared to local-intraarterial thrombolysis in carotid $\mathrm{T}$ and

AJNR Am J Neuroradiol 37:673-78 Apr 2016 www.ajnr.org 
middle cerebral artery occlusions: a single center experience. Clin Neuroradiol 2012;22:141-47 CrossRef Medline

5. Shi ZS, Loh Y, Walker G, et al. Clinical outcomes in middle cerebral artery trunk occlusions versus secondary division occlusions after mechanical thrombectomy: pooled analysis of the Mechanical Embolus Removal in Cerebral Ischemia (MERCI) and Multi MERCI trials. Stroke 2010;41:953-60 CrossRef Medline

6. Frahm D, Wunderlich S, Schubert MI, et al. Mechanical thrombectomy in acute occlusion of the carotid-T: a retrospective single centre study in 51 patients. Clin Neuroradiol 2014 Jul 25. [Epub ahead of print] CrossRef Medline

7. Kurre W, Vorlaender K, Aguilar-Pérez M, et al. Frequency and relevance of anterior cerebral artery embolism caused by mechanical thrombectomy of middle cerebral artery occlusion. AJNR Am J Neuroradiol 2013;34:1606-11 CrossRef Medline

8. King S, Khatri P, Carrozella J, et al; IMS \& IMS II Investigators. Anterior cerebral artery emboli in combined intravenous and intraarterial rtPA treatment of acute ischemic stroke in the IMS I and II trials. AJNR Am J Neuroradiol 2007;28:1890-94 CrossRef Medline

9. Stampfl S, Kabbasch C, Muller M, et al. Initial experience with a new distal intermediate and aspiration catheter in the treatment of acute ischemic stroke: clinical safety and efficacy. J Neurointervent Surg 2015 May 29. [Epub ahead of print] CrossRef Medline

10. Chueh JY, Kühn AL, Puri AS, et al. Reduction in distal emboli with proximal flow control during mechanical thrombectomy: a quantitative in vitro study. Stroke 2013;44:1396-401 CrossRef Medline

11. Chueh JY, Puri AS, Wakhloo AK, et al. Risk of distal embolization with stent retriever thrombectomy and ADAPT. J Neurointervent Surg 2014 Dec 24. [Epub ahead of print] CrossRef Medline

12. Nguyen TN, Malisch T, Castonguay AC, et al. Balloon guide catheter improves revascularization and clinical outcomes with the Solitaire device: analysis of the North American Solitaire Acute Stroke Registry. Stroke 2014;45:141-45 CrossRef Medline

13. Turk AS, Frei D, Fiorella D, et al. ADAPT FAST study: a direct aspiration first pass technique for acute stroke thrombectomy. J Neurointervent Surg 2014;6:260-64 CrossRef Medline

14. Alonso A, Gass A, Rossmanith C, et al. Clinical and MRI patterns of pericallosal artery infarctions: the significance of supplementary motor area lesions. J Neurol 2012;259:944-51 CrossRef Medline

15. Lehecka M, Dashti R, Hernesniemi J, et al. Microneurosurgical management of aneurysms at the $\mathrm{A} 2$ segment of anterior cerebral artery (proximal pericallosal artery) and its frontobasal branches. Surg Neurol 2008;70:232-46; discussion 246 CrossRef Medline

16. Hacke W, Kaste M, Fieschi C, et al. Randomised double-blind placebo-controlled trial of thrombolytic therapy with intravenous alteplase in acute ischaemic stroke (ECASS II): Second EuropeanAustralasian Acute Stroke Study Investigators. Lancet 1998;352: 1245-51 CrossRef Medline
17. Smith WS, Sung G, Starkman S, et al; MERCI Trial Investigators. Safety and efficacy of mechanical embolectomy in acute ischemic stroke: results of the MERCI trial. Stroke 2005;36:1432-38 CrossRef Medline

18. Möhlenbruch M, Stampfl S, Behrens L, et al. Mechanical thrombectomy with stent retrievers in acute basilar artery occlusion. AJNR Am J Neuroradiol 2014;35:959-64 CrossRef Medline

19. Rha JH, Saver JL. The impact of recanalization on ischemic stroke outcome: a meta-analysis. Stroke 2007;38:967-73 CrossRef Medline

20. Dorn F, Lockau H, Stetefeld H, et al. Mechanical thrombectomy of M2-occlusion. J Stroke Cerebrovasc Dis 2015;24:1465-70 CrossRef Medline

21. Dorn F, Stehle S, Lockau H, et al. Endovascular treatment of acute intracerebral artery occlusions with the Solitaire stent: single-centre experience with 108 recanalization procedures. Cerebrovasc Dis 2012;34:70-77 CrossRef Medline

22. Pereira VM, Gralla J, Davalos A, et al. Prospective, multicenter, single-arm study of mechanical thrombectomy using Solitaire flow restoration in acute ischemic stroke. Stroke 2013;44:2802-07 CrossRef Medline

23. Haussen DC, Lima A, Nogueira RG. The Trevo XP 3x20 mm retriever ('Baby Trevo') for the treatment of distal intracranial occlusions. J Neurointervent Surg 2015 May 6. [Epub ahead of print] CrossRef Medline

24. Behme D, Gondecki L, Fiethen S, et al. Complications of mechanical thrombectomy for acute ischemic stroke-a retrospective singlecenter study of 176 consecutive cases. Neuroradiology 2014;56: 467-76 CrossRef Medline

25. Akins PT, Amar AP, Pakbaz RS, et al; SWIFT Investigators. Complications of endovascular treatment for acute stroke in the SWIFT trial with Solitaire and Merci devices. AJNR Am J Neuroradiol 2014; 35:524-28 CrossRef Medline

26. Singer OC, Berkefeld J, Nolte $\mathrm{CH}$, et al. Collateral vessels in proximal middle cerebral artery occlusion: the ENDOSTROKE study. Radiology 2015;274:851-58 CrossRef Medline

27. Souza LC, Yoo AJ, Chaudhry ZA, et al. Malignant CTA collateral profile is highly specific for large admission DWI infarct core and poor outcome in acute stroke. AJNR Am J Neuroradiol 2012;33: 1331-36 CrossRef Medline

28. Saver JL. Time is brain: quantified. Stroke 2006;37:263-66 CrossRef Medline

29. Ribo M, Flores A, Mansilla E, et al. Age-adjusted infarct volume threshold for good outcome after endovascular treatment. J Neurointervent Surg 2014;6:418-22 CrossRef Medline

30. Navia P, Larrea JA, Pardo E, et al. Initial experience using the 3 MAX cerebral reperfusion catheter in the endovascular treatment of acute ischemic stroke of distal arteries. J Neurointervent Surg 2015 Jul 15. [Epub ahead of print] CrossRef Medline 